\title{
A Qualitative Study on Coping Strategies Among Patients with Non-Specific Low-Back Pain
}

\author{
Adesola Ojo Ojoawo (ib ${ }^{1,}{ }^{*}$, Taiwo Oluwaseun Arasanmi ${ }^{1}$ and Chidozie Emmanuel Mbada (iD ${ }^{1}$ \\ ${ }^{1}$ Department of Medical Rehabilitation, Faculty of Basic Medical Sciences, College of Health Sciences, Obafemi Awolowo University, Ile Ife, Nigeria \\ "Corresponding author: Department of Medical Rehabilitation, Faculty of Basic Medical Sciences, College of Health Sciences, Obafemi Awolowo University, Ile Ife, Nigeria. Tel: \\ +234-8033567577, Email: aoojoawo@yahoo.com
}

Received 2020 April 06; Revised 2020 June 01; Accepted 2020 June 01.

\begin{abstract}
Background: Non-specific low-back pain (NSLBP) is a common health problem worldwide, but the perception and coping strategies used by patients are underreported.

Objectives: The objectives of the study were to evaluate the perception of patients with NSLBP, the ways the pain interrfered with their basic life, and coping strategies employed by them.

Methods: Twenty patients consisting of 10 males (50\%) and 10 females (50\%) participated in this study. A qualitative interview was conducted using a three-section modified structured interview guide by Gwenda. Section A contained sociodemographic information, section B was the numerical pain rating scale, and section $\mathrm{C}$ asked questions about the pain duration, the ways of pain interference with the patient's life, and strategies used to cope with pain. The data were analyzed using thematic content analysis. Results: The results showed that $50 \%$ of the patients were within the age range of 58 years or above. Ten (50\%) patients perceived that NSLBP was caused by work-related activities and 10\% perceived that NSLBP was a spiritual problem. Fifty percent reported that the pain interfered with their activities of daily living, and four (20\%) mentioned that NSLBP interfered with their sexual function and religious activities. Concerning the coping strategy, 40\% used prayer, $15 \%$ usually ignored the pain, and $35 \%$ used the conventional approach.

Conclusions: It can be concluded that half of the patients with NSLBP perceived NSLBP to be caused by work-related activities. Besides, NSLBP interfered with basic activities of daily living, and about 40\% were coping with NSLBP with prayer and spiritual means.
\end{abstract}

Keywords: Non-Specific Low-Back Pain, Coping Strategies, Perception, Pain Intensity, Praying

\section{Background}

According to the Global Burden of Disease 2010, nonspecific low back pain (NSLBP) was considered to be among the top 10 highly burden diseases and injuries (1). Low-back pain is a condition that affects a significant proportion of the general population. The perception and opinions of this condition among patients will affect their healthseeking behavior, compliance with preventive measures, and invariably the perception of the disease by the general population (2). Omokhodion et al. (3) reported that more than $70 \%$ of respondents among nurses believed that NSLBP was caused by work-related activities. In addition, according to Shah and Dave (4), 64.44\% of the medical doctors in Surat, India, agreed that the occurrence of NSLBP was related to work activities, and close to $75 \%$ had incurred NSLBP when they started working. The study reported that among health workers, LBP was perceived to be due to long hours of standing, awkward postures, and carrying heavy objects or patients at work (5). Concerning the coping strategies, Cabak et al. (6) reported that the most common coping strategies adopted by patients were prayer, hope, and increased behavioral activities.

Previous studies have established a strong association between psychosocial factors and low back pain $(7,8)$, but the strategies employed by patients to cope with low back pain have not been well documented. Also, studies have established the perception of health workers on LBP (3-5) but this concept is not yet well studied among patients with NSLBP. Besides, coping strategies employed by patients with NSLBP, especially in this environment, have not been thoroughly investigated.

\section{Objectives}

Thus, a study was designed to evaluate the perception of patients with NSLBP, the ways that the pain interferes 
with basic life, and coping strategies employed by the patients using a qualitative approach.

\section{Methods}

A cross-sectional study was conducted on a total of 20 patients with NSLBP who were recruited using a purposive sampling method. Ethical approval (no.: IRB/IEC/0004553; ERC/2018/11/03) was obtained from the Ethics and Research Committee of the Teaching Hospital affiliated to the Obafemi Awolowo University, Ile-Ife. The informants for this study were patients with low-back pain receiving treatment at the Physiotherapy Clinic of Teaching Hospitals of the Obafemi Awolowo University. The inclusion criteria were a) patients with low-back pain between 18 and 65-years-old, b) patients with NSLBP that referred to attend their second treatment session, and c) patients with low-back pain who were literate in English or Yoruba languages. Patients with low-back pain that had cognitive impairment or had their first visit for physiotherapy treatments were excluded from the study.

\subsection{Instruments}

An android phone was used for the recording of interview sessions with the informants in a language they understood using the modified structured interview guide on coping strategies by Gwenda (9). The structured interview guide contained three sections. Section A contained some questions on sociodemographic information of the patients, such as age, sex, educational status, marital status, and nature of work. Section B contained the numerical pain rating scale used to assess the intensity of the pain. The scale ranged from 0 to $10(0=$ no pain or discomfort, $2=$ little or insignificant pain, $4=$ moderate or not severe discomfort, 6 = serious discomfort, $8=$ very serious discomfort, 10 = excruciating pain).

Section $C$ contained questions about the pain such as the duration of the patient's pain, the patient's perception about the pain, pain interference with the patient's life, coping strategies with the pain, the source of most support for the patient in coping with the pain, other management methods for coping with pain apart from physiotherapy, the management they thought to work effectively for them, and barriers to their pain management. The coping strategies questionnaire was found to be specifically and importantly related to the chronic pain inventory in all subscales (10). For reliability, the coping strategies questionnaire as a whole scale had a Cronbach's alpha of 0.94 and an intra-class correlation coefficient of 0.89 (95\% CI: 0.86 - 0.98$)(11)$.

\subsection{Procedure}

Eligible informants who met the inclusion criteria were given information about the interview by the researcher and verbal consent was obtained from each informant before the interview. A qualitative interview was conducted using the modified structured interview guide on coping strategies by Gwenda (9) in a language the interviewees understood. The interviews took place at the Physiotherapy Clinic of Obafemi Awolowo University, IleIfe. Each interview lasted approximately 20 minutes and was recorded with an android phone. Written consent was obtained at the interview session.

\subsection{Analysis of Collected Variables}

The collected variables, especially the biodata, from the informant, were summarized using mean, standard deviation, and frequency distribution. The interviews with the informants were done and then documented by the researcher verbatim. Informants were given initials that were not related to their original names. As the collection of the variables was going on, important information was picked and analyzed by studying and re-studying the recorded information by the researcher and the analyst. Having finished the collection and assigning symbols to the variables, the researcher and the analyst reviewed the content and decided on the agreed themes. The data were analyzed using thematic content analysis. Data saturation was reached with respondent 19 , but the analysis was extended subsequently to informant 20.

\section{Results}

\subsection{Sociodemographic Data and Clinical Features of Infor-} mants

Table 1 presents the sociodemographic variables and the manifestation of the pain in the patients. Twenty subjects with pain at low back participated in this study. The mean age, pain level, and pain duration were $53.9 \pm 16.0$ years, $4.4 \pm 1.2$, and $86.3 \pm 54.0$ days, respectively. There were equal males and females in the study. Also, 50\% were degree holders, 70\% were married, $20 \%$ had severe pain intensity, and 50\% had pain for more than six months.

\subsection{Qualitative Analysis}

\subsubsection{Informant Perception of Low Back Pain}

The concept of pain seems to be understood by the majority (50\%) of the patients as a result of work-related activities (Table 2). For example, an informant stated, "I think the pain is a result of the stress I underwent during childbirth and old age" (BKA).

Ten percent of the informants attributed their pain to spiritual and natural events. For example, an informant 


\begin{tabular}{|c|c|}
\hline Variables & No. (\%) or Mean \pm SD \\
\hline Age, $y$ & $53.9 \pm 16.09$ \\
\hline$\leq 30$ & $1(5)$ \\
\hline $31-57$ & $9(45)$ \\
\hline$\geq 58$ & $10(50)$ \\
\hline \multicolumn{2}{|l|}{ Sex } \\
\hline Male & $10(50)$ \\
\hline Female & $10(50)$ \\
\hline \multicolumn{2}{|l|}{ Education } \\
\hline No formal education & $2(10)$ \\
\hline Primary & $3(15)$ \\
\hline Tertiary Education & $10(50)$ \\
\hline Masters & $2(10)$ \\
\hline \multicolumn{2}{|l|}{ Marital status } \\
\hline Single & $1(5)$ \\
\hline Having husband/wife & $14(70)$ \\
\hline Not living with husband/wife & $1(5)$ \\
\hline Dead husband/wife & $4(20)$ \\
\hline \multicolumn{2}{|l|}{ Occupation } \\
\hline Civil servant & $6(30)$ \\
\hline Trader & $6(30)$ \\
\hline Farmer & $5(25)$ \\
\hline Retiree & $3(15)$ \\
\hline \multicolumn{2}{|l|}{ Pain level } \\
\hline Low & $10(50)$ \\
\hline Moderate & $6(30)$ \\
\hline Severe & $4(20)$ \\
\hline \multicolumn{2}{|l|}{ Pain duration, $\mathbf{d}$} \\
\hline $21-90$ & $3(15)$ \\
\hline $91-270$ & $7(35)$ \\
\hline$\geq 27$ & $10(50)$ \\
\hline
\end{tabular}

\begin{tabular}{lc}
\hline Table 2. The Perception of Pain & \\
\hline Variable & Values \\
\hline Pain is a spiritual problem & $2(40)$ \\
Pain is caused by work-related activities & $10(50)$ \\
\hline Pain is a familiar cause & $1(5)$ \\
\hline Pain has grave consequences & $3(15)$ \\
\hline There is still hope with time & $4(20)$ \\
\hline
\end{tabular}

${ }^{\mathrm{a}}$ Values are expressed as No. (\%). said "I don't perceive it (pain) as a problem ... my mother had the same problem when she was alive at her old age" (LOO). Articulating their perceptions, some of the informants felt that living with pain brought them to their wit's end, while some saw hope in sight. Specifically, some said "... I know I can live with it, and it will continue to improve till God calls me" (ATO). In contrast, an informant in shock stated: “... it just started suddenly, and I think I'm too young to be experiencing low-back pain" (ILO), while another informant threw in the towel about having pain, saying "probably that's how God wants it to be" (BKA).

\subsubsection{Interference of Pain with Normal Life}

There was almost a consensus that low-back pain interferes with the normal life of the patients. Some informants (65\%) narrated that their pain altered their normal living and hindered their performance in most domains of basic and instrumental activities of daily living (Table 3). Some of the informants (15\%) recounted that LBP altered especially their posture and walking.

\begin{tabular}{lc}
\hline Table 3. Interference of Pain with Normal Life ${ }^{\mathrm{a}}$ & \multicolumn{1}{l}{ Values } \\
\hline Variable & $10(50)$ \\
\hline Pain interferes with basic activities of daily living & $3(15)$ \\
\hline Pain interferes with instrumental activities of daily living & $3(15)$ \\
\hline Pain interferes with walking and posture & $4(20)$ \\
\hline $\begin{array}{l}\text { Pain interferes with sexual life, social functions, and religious } \\
\text { duties }\end{array}$ & \\
\hline${ }^{\mathrm{a} V a l u e s}$ are expressed as No. (\%).
\end{tabular}

4.2.3. Coping Strategies with Low-Back Pain (Catastrophization, Ignore, Diversion (Distraction), Re-Interpretation, Prayer, Hope)

The informants in this study expressed different types of ways to cope with LBP. Mostly, their coping practices were centered on diversion (10\%) and seeking spiritual interventions (40\%) by praying, rather than applying conventional therapeutic means. Table 4 shows the information on coping strategies adopted by informants for low-back pain management.

\begin{tabular}{lc}
\hline Table 4. Coping Strategies Adopted by Informants for Pain Management ${ }^{\mathrm{a}}$ \\
\hline Strategy & Values \\
\hline Ignoring & $03(15.00)$ \\
Diversion & $02(10.00)$ \\
\hline Praying and spiritual approach & $08(40.00)$ \\
\hline Conventional approach & $07(35.00)$ \\
\hline
\end{tabular}

${ }^{\mathrm{a}}$ Values are expressed as No. (\%) 


\subsubsection{Source of Support for Pain Coping in Low-Back Pain}

The finding of the study showed that patients with lowback pain received support from varying sources ranging from family, peers, and health professionals. Support from family (55\%) was mostly reported by the patients in this study (Table 5).

Table 5. Sources of Support ${ }^{\mathrm{a}}$

\begin{tabular}{lc}
\hline Source & Values \\
\hline Family only & $11(55)$ \\
\hline Peers only & $2(10)$ \\
\hline Peers and family & $3(15)$ \\
\hline Health professionals & $1(5)$ \\
\hline None & $3(15)$ \\
\hline
\end{tabular}

${ }^{\mathrm{a}}$ Values are expressed as No. (\%).

\subsubsection{Perception of the Effectiveness of Interventions for Coping} with Low-Back Pain

Most of the informants were involved in mixed practices for their low-back pain, and as such, have the perception that bothers on the intervention received. For example, some said "I can't say which one is effective" (LOO) ...", "I don't know. But I feel relieved with the two" (QTB), "I can't say because I still use the lotion before coming to the clinic" (TAB). Yet, some informants (55\%) still spoke about their perception of conventional interventions they received (Table 6).

\begin{tabular}{lc}
\hline Table 6. Perception of Effectiveness of Interventions $^{\mathrm{a}}$ & \\
\hline Intervention & Values \\
\hline Conventional intervention, i.e. therapy plus medication & $11(55)$ \\
Traditional intervention & $1(5)$ \\
Mixed intervention & $3(15)$ \\
Cannot really say & $5(25)$ \\
\hline
\end{tabular}

${ }^{a}$ Values are expressed as No. (\%).

\section{Discussion}

This study investigated the perception of patients with NSLBP, the ways that pain interfered with basic life, and coping strategies employed by patients in the Physiotherapy Clinic of the Teaching Hospitals of the Obafemi Awolowo University, Ile-Ife.

The study showed that the informants had a different perception of low-back pain. Half of the informant perceived NSLBP as a result of work-related activities, 15\% perceived it to have grave consequences, while a few numbers perceived it as a spiritual problem. This supports a previous study by Hoy (12) that showed the ways people perceived pain were quite different from each other. That other factors may contribute to the causes of back pain makes it very difficult to identify the origins. The Awosan et al. (5) study was in tandem with our findings especially on the perception that NSLBP is caused by work-related activities. One of the costliest disorders worldwide is lowback pain. Sitting and activities such as vibration and awkward postures, especially at workplaces, have been identified to be major contributory factors to this pain (13). The results of this study showed that low-back pain has a significant effect on all aspects of living as stated in the questionnaire, including basic and instrumental activities of daily living, sex, and social lives. These results corroborated the work by Dagenais et al. (14) that functional capacity, occupational activities, and absenteeism from workplaces are significantly influenced by pain at low back. Bener et al. (15) also reported that low-back pain has a substantial negative impact on the quality of life of the patients. There is nobody that is in pain and still can perform his optimum in any area of life. Kose and Hatipoglu (16) concluded in their study that patients with low-back pain experience physical disabilities due to pain. Their daily living activities are affected by these disabilities, and the intensity of pain affects the level of disability.

In addition, it was shown in the study that the most commonly used strategy by the informants was praying and spiritual approach while catastrophizing was a rare practice among the informants. Our study was in line with a report by Caba et al. (6) but slightly in contradiction to findings by Misterska et al. (17), who reported that the chosen strategies were catastrophizing and praying/hoping. This is due to their different religious belief that whatever happens to them comes from God. As a result, they preferred to seek God's help than medical intervention. People in the southwestern part of Nigeria are found to be highly religious, because they pray regularly either in Christian or Muslim way, therefore this is reflected in the coping strategies with non-specific low-back pain. It could be recalled that a percentage of the informant stated that pain is a spiritual problem. Such kind of individuals will seek a way to cope through spiritual means, and the foremost means is prayer. In addition, the results also revealed that more than $50 \%$ of the informants could not attribute the barriers to seeking management of pain to anything. The inference is that it is not in their habit to seek any medical intervention. They possibly rely majorly on spiritual interventions or ignore the pain, another reason why there were patients with pain for more than 270 days. This may eventually lead to deformity or postural imbalance. 


\subsection{Limitations of the Study}

One of the limitations of the study was that the information given by the informants was believed to be true. This was because, based on the poor economic status of many patients, some might have the notion that there might be a financial assistance from the researcher, thereby given information that may attract attention. Another limitation is that few patients had subacute low-back pain. They were not screened out because the preponderance of patients, especially at the department, was very poor. Besides, many studies were going on simultaneously on patients with low-back pain at this period.

\subsection{Conclusions}

In line with numerous studies, it can be concluded that average patients with NSLBP perceived NSLBP to be caused by work-related activities, NSLBP interfered with basic activities of daily living, and about $40 \%$ of the patients were coping with NSLBP with prayer and spiritual means. It is suggested that patients with low-back pain be enlightened on different treatments for low-back pain, including coping strategies.

\section{Footnotes}

Authors' Contribution: Adesola Ojo Ojoawo designed the study, analyzed the data, interpreted the data, and did the critical reading of the final write-up. Taiwo Oluwaseun Arasanmi collected the data, searched the literature, and did the skeletal write-up. Chidozie Emmanuel Mbada made the interpretation of the data and critical reading for publication.

Conflict of Interests: No conflict of interest is reported by any author.

Ethical Approval: Ethical approval (no.: IRB/IEC/0004553; ERC/2018/11/03) was obtained from Obafemi Awolowo University Teaching Hospitals Complex, Ile-Ife.

Funding/Support: No funding support was received from any organization.

Informed Consent: Inform concept was obtained from the participants in the study.

\section{References}

1. Vos T, Flaxman AD, Naghavi M, Lozano R, Michaud C, Ezzati M, et al. Years lived with disability (YLDs) for 1160 sequelae of 289 diseases and injuries 1990-2010: A systematic analysis for the Global Burden of Disease Study 2010. Lancet. 2012;380(9859):2163-96. doi: 10.1016/S0140-6736(12)61729-2. [PubMed: 23245607]. [PubMed Central: PMC6350784].
2. CDC. Preventing back injuries in health care settings. Atlanta, USA: Centers for Disease Control and Prevention; 2008. Available from: http//: blogs.cdc.gov/niosh-science-blog/2008/09/22/lifting.

3. Omokhodion FO, Umar US, Ogunnowo BE. Prevalence of low back pain among staff in a rural hospital in Nigeria. Occup Med (Lond). 2000;50(2):107-10. doi: 10.1093/occmed/50.2.107. [PubMed: 10829430].

4. Shah S, Dave B. Prevalence of low back pain and its associated risk factors among doctors in Surat. Int J Heal Sci Res. 2012;2(1):1-5.

5. Awosan KJ, Yikawe SS, Oche OM, Oboirien M. Prevalence, perception and correlates of low back pain among healthcare workers in tertiary health institutions in Sokoto, Nigeria. Ghana Med J. 2017;51(4):164-74. [PubMed: 29622830]. [PubMed Central: PMC5870785].

6. Cabak A, Dabrowska-Zimakowska A, Truszczynska A, Rogala P, Laprus $\mathrm{K}$, Tomaszewski W. Strategies for coping with chronic lower back pain in patients with long physiotherapy wait time. Med Sci Monit. 2015;21:3913-20. doi: 10.12659/msm.894743. [PubMed: 26670743]. [PubMed Central: PMC4734674].

7. Ramirez-Maestre C, Esteve R, Lopez AE. Cognitive appraisal and coping in chronic pain patients. Eur J Pain. 2008;12(6):749-56. doi: 10.1016/j.ejpain.2007.11.004. [PubMed: 18096418].

8. Davis KG, Heaney CA. The relationship between psychosocial work characteristics and low back pain: Underlying methodological issues. Clin Biomech (Bristol, Avon). 2000;15(6):389-406. doi: 10.1016/s0268-0033(99)00101-1. [PubMed: 10771118].

9. Lansbury G. Chronic pain management: A qualitative study of elderly people's preferred coping strategies and barriers to management. Disabil Rehabil. 2000;22(1-2):2-14. doi: 10.1080/096382800297079-1. [PubMed: 10661753].

10. Hadjistavropoulos HD, MacLeod FK, Asmundson GJ. Validation of the chronic pain coping inventory. Pain. 1999;80(3):471-81. doi: 10.1016/s0304-3959(98)00224-3. [PubMed: 10342409].

11. Verra ML, Angst F, Lehmann S, Aeschlimann A. Translation, crosscultural adaptation, reliability, and validity of the German version of the Coping Strategies Questionnaire (CSQ-D). J Pain. 2006;7(5):327-36. doi: 10.1016/j.jpain.2005.12.005. [PubMed: 16632322].

12. Hoy D, Bain C, Williams G, March L, Brooks P, Blyth F, et al. A systematic review of the global prevalence of low back pain. Arthritis Rheum. 2012;64(6):2028-37. doi: 10.1002/art.34347. [PubMed: 22231424].

13. Lis AM, Black KM, Korn H, Nordin M. Association between sitting and occupational LBP. Eur Spine J. 2007;16(2):283-98. doi: 10.1007/s00586006-0143-7. [PubMed: 16736200]. [PubMed Central: PMC2200681].

14. Dagenais S, Tricco AC, Haldeman S. Synthesis of recommendations for the assessment and management of low back pain from recent clinical practice guidelines. Spine J. 2010;10(6):514-29. doi: 10.1016/j.spinee.2010.03.032. [PubMed: 20494814].

15. Bener A, Verjee M, Dafeeah EE, Falah O, Al-Juhaishi T, Schlogl J, et al. Psychological factors: Anxiety, depression, and somatization symptoms in low back pain patients. J Pain Res. 2013;6:95101. doi: 10.2147/JPR.S40740. [PubMed: 23403693]. [PubMed Central: PMC3569050].

16. Kose G, Hatipoglu S. The effect of low back pain on the daily activities of patients with lumbar disc herniation: A Turkish military hospital experience. J Neurosci Nurs. 2012;44(2):98-104. doi: 10.1097/JNN.ob013e3182478e57. [PubMed: 22367273].

17. Misterska E, Jankowski R, Glowacki M. Psychometric properties of the Polish language version of the chronic pain coping inventory-42 for patients treated surgically due to herniated lumbar discs and spondylotic changes. Med Sci Monit. 2014;20:789-801. doi: 10.12659/MSM.889728. [PubMed: 24824781]. [PubMed Central: PMC4031224]. 